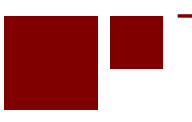

C E N T E R for RETIREMENT RES E A R C H at BOSTON COLLEGE

\title{
ACTUARIAL INPUTS AND THE VALUATION OF PUBLIC PENSION LIABILITIES AND CONTRIBUTION REQUIREMENTS: A SIMULATION APPROACH
}

\author{
Gang Chen and David S. T. Matkin
}

CRR WP 2017-4

May 2017

\author{
Center for Retirement Research at Boston College \\ Hovey House \\ 140 Commonwealth Avenue \\ Chestnut Hill, MA 02467 \\ Tel: 617-552-1762 Fax: 617-552-0191 \\ http://crr.bc.edu
}

Both authors are with the Rockefeller College of Public Affairs and Policy at the State University of New York at Albany (SUNY Albany). Gang Chen is an assistant professor and David S. T. Matkin is an assistant professor and vice chair. The research reported herein was pursuant to a grant from the U.S. Social Security Administration (SSA) funded as part of the Retirement Research Consortium. The findings and conclusions expressed are solely those of the authors and do not represent the views of SSA, any agency of the federal government, SUNY Albany, or Boston College. Neither the United States Government nor any agency thereof, nor any of their employees, makes any warranty, express or implied, or assumes any legal liability or responsibility for the accuracy, completeness, or usefulness of the contents of this report. Reference herein to any specific commercial product, process or service by trade name, trademark, manufacturer, or otherwise does not necessarily constitute or imply endorsement, recommendation or favoring by the United States Government or any agency thereof.

(C) 2017, Gang Chen and David S. T. Matkin. All rights reserved. Short sections of text, not to exceed two paragraphs, may be quoted without explicit permission provided that full credit, including (C) notice, is given to the source. 


\title{
About the Steven H. Sandell Grant Program
}

This paper received funding from the Steven H. Sandell Grant Program for Junior Scholars in Retirement Research. Established in 1999, the Sandell program's purpose is to promote research on retirement issues by scholars in a wide variety of disciplines, including actuarial science, demography, economics, finance, gerontology, political science, psychology, public administration, public policy, sociology, social work, and statistics. The program is funded through a grant from the Social Security Administration (SSA). For more information on the Sandell program, please visit our website at: http://crr.bc.edu/?p=9570, send e-mail to crr@bc.edu, or call (617) 552-1762.

\section{About the Center for Retirement Research}

The Center for Retirement Research at Boston College, part of a consortium that includes parallel centers at the University of Michigan and the National Bureau of Economic Research, was established in 1998 through a grant from the Social Security Administration. The Center's mission is to produce first-class research and forge a strong link between the academic community and decision-makers in the public and private sectors around an issue of critical importance to the nation's future. To achieve this mission, the Center sponsors a wide variety of research projects, transmits new findings to a broad audience, trains new scholars, and broadens access to valuable data sources.

\author{
Center for Retirement Research at Boston College \\ Hovey House \\ 140 Commonwealth Ave \\ Chestnut Hill, MA 02467 \\ Tel: 617-552-1762 Fax: 617-552-0191 \\ http://crr.bc.edu
}

Affiliated Institutions:

The Brookings Institution

Syracuse University

Urban Institute 


\begin{abstract}
This paper uses a simulated public pension system to examine the sensitivity of actuarial input changes on funding ratios and contribution requirements. We examine instantaneous and lagged effects, marginal and interactive effects, and effects under different funding conditions and demographic profiles. The findings emphasize the difficulty of conducting cross-sectional analyses of public pension systems and point to several important considerations for future research.
\end{abstract}

The paper found that:

- Discount rates, salary growth rates, cost methods, and mortality tables all influence funding ratios and contribution requirements. Without considering these effects, comparisons of funding ratios across pension systems will produce biased results.

- The discount rate assumption is the most influential actuarial input on funding ratios and contribution requirements. We show that a plan can postpone required contributions by raising its discount rate assumption, but its funding condition deteriorates in the long run. In contrast, if a plan reduces its discount rate by 1 percentage point, and its investment returns continue at the level that was previously assumed, it will take approximately seven years for the funding ratio to return to its original level and an even longer time period for the ARC to return to its original level (though the exact length of time depends on investment returns and the baseline discount rate assumption).

- The effects of actuarial inputs greatly depend on plan characteristics such as demographic profiles and asset levels, and also interactions with other actuarial inputs. Because of the interactive effects, it is difficult to standardize funding ratios or pension obligations by only controlling for a single actuarial input. With better data on plan characteristics (such as information on mortality tables and age distributions), simulations could be used to standardize pension liabilities. In the absence of that information, improved consistency in financial reporting (such as requiring a single cost method) is an effective way to facilitate better comparisons of financial conditions across pension plans. 
The policy implications of the findings are:

- The valuation (or measurement) of public pension liabilities and contribution requirements is highly sensitive to the choice of several actuarial assumptions, which should be considered when assessing the financial condition of public pension systems.

- The sensitivity of liability and contribution requirement valuations to actuarial assumptions and methods depends on the demographic profile of pension participants.

- Making more optimistic assumptions reduces the liability and contribution valuations in the short term, but, over time, more optimistic assumptions can have substantive and harmful effects on pension liabilities and contribution requirements. 


\section{Introduction}

The financial condition of public pensions has drawn significant scrutiny in recent years. Much of that attention focuses on the effect of actuarial assumptions and methods on the accuracy of pension liabilities and the adequacy of sponsor funding practices. For example, there is an active debate on whether public pensions should continue to use discount rates that reflect historical investment returns (NASRA 2015) or select actuarial discount rates that reflect the certainty of future benefit payments (Biggs 2012; Novy-Marx and Rauh 2011). In 2013, Moody’s Investor Services adopted its own actuarial procedures to evaluate the financial condition of public sector pension systems, rather than rely on valuations reported under generally accepted accounting principles (Moody’s 2013). And, the Governmental Accounting Standards Board recently revised pension accounting standards (GASB 67 and 68) to significantly change the way actuarial inputs affect financial reporting (GASB 2012).

Despite the clear professional and policy relevance of actuarial assumptions and methods in evaluating the financial condition of public pensions, to date, research into the effect of actuarial inputs on public pensions is limited. In this paper, the term "actuarial inputs" refers to the set of assumptions and methods used by actuaries to value pension liabilities and contribution requirements.

One significant limitation of the extant literature is that it often entirely overlooks actuarial inputs. The clearest examples are the many studies that model the financial condition of public pensions without including any controls for actuarial inputs (Coggburn and Kearney 2010; Kelly 2014; Marks, Raman and Wilson 1988; Schneider and Damanpour 2002; St. Clair 2013; Thom 2013). Another way that the literature overlooks actuarial inputs is by failing to include several influential assumptions and methods in their models. For example, we were able to identify only one study that controls for the different actuarial cost methods (Giertz and Papke 2007) and another that controls for mortality rate assumptions (Munnell, Aubry and Cafarelli 2015). These omissions are surprising because actuarial inputs are known to have mathematically deterministic and potentially salient effects on pension liabilities and contribution requirements (Peng 2008).

A second limitation in the literature is the inconsistency in the parameter estimates for those actuarial inputs that have received more attention (i.e., discount rate and salary growth rate assumptions). Several studies fail to find relationships between the financial conditions of public 
pensions and their discount rates (Dulebohn 1995; Mitchell and Hsin 1994; Rich and Zhang 2014) and salary growth rates (Dulebohn 1995; Mitchell and Hsin 1994; Hsin and Mitchell 1994; Eaton and Nofsinger 2004). One study estimates the effect of discount rates to be significantly larger than the effect of salary growth rate assumptions (Eaton and Nofsinger 2004), while another shows that discount rates and salary growth rates have similar effects (Mitchell and Smith 1994). These inconsistencies further confuse our understanding of the effects of actuarial inputs.

A third limitation of the existing research is that it assumes a constant, simultaneous relationship between discount rates and the financial condition of public pensions. All of the studies that regress the financial condition of public pensions on discount rates specify a linear relationship (Mitchell and Smith 1994; Hsin and Mitchell 1994; Rich and Zhang 2014; Triest and Zhao 2013). Other researchers assume a linear relationship in the way that they attempt to standardize financial conditions across multiple pension systems using different discount rates and salary growth rates. For example, Chaney, Copely, and Stone (2002) created a standardized measure of pension benefit obligations by assuming that every 25 basis point change in discount rates will change pension benefit obligations by 4 percent. Eaton and Nofsinger (2004) create a standardized measure of annual required contributions (ARCs) by estimating the predicted ARC for each of the pension systems in their sample as the linear function of their discount rates, salary growth rates, and amortization periods. Because the extant research has only attempted to estimate a linear relationship between the financial condition of public pensions and their actuarial inputs, we know little about potential non-linear or interactive effects from actuarial inputs.

Given these limitations in our understanding about the relationship between actuarial inputs and the valuation of public pensions' financial conditions, we seek to make three contributions. First, we use a simulated pension system to measure the marginal effects of changes in four actuarial inputs: actuarial cost methods, discount rate assumptions, salary growth rate assumptions, and mortality rate assumptions. Specifically, we test whether the marginal effects of discount rate changes are similar to the marginal effects of changes to other actuarial inputs.

Second, we examine both the instantaneous and lagged effects of marginal changes to discount rate assumptions. We do this by examining the lagged effect of a 1-percentage-point 
increase and decrease to the discount rate assumption while holding investment performance constant, and then identifying how long it takes a simulated pension system's funding ratio and contribution rate to return to their original levels.

Third, we test the effect of changes to pension systems under a variety of conditions to test for non-linear effects, such as (1) interactive effects with other actuarial inputs; (2) effects under different funding conditions; and (3) effects under different demographic profiles. We then use the analysis to examine the likelihood of standardizing the financial condition data that is reported by actual public pension systems.

To accomplish these aims, we simulate pension plans with different demographic profiles and asset levels, and then calculate changes in liability valuations and contribution requirements under different values of four actuarial inputs (discount rates, salary growth rates, actuarial cost methods, and mortality tables).

This paper proceeds in the following order. In the first section, we discuss the actuarial process. Then, we describe the relationship between actuarial inputs and pension management. After which, we discuss each of the four actuarial inputs examined in this study. Then, we describe the simulation and present its results. We conclude with a discussion of key findings, study limitations, and suggestions for further research.

\section{The Actuarial Process}

Pension actuarial science is the process of evaluating assets and liabilities in a pension plan (Ezra 1980). Pension liabilities are valuations of the retirement payments that pension plans expect to make to qualified pension plan participants and their beneficiaries. From a plan sponsor's perspective, the actuarial process helps (1) calculate the present value of their future retirement payments and (2) develop a savings strategy to help them smooth the budgetary costs of the pension benefits over the time period when their employees are working and earning their pension benefits.

The actuarial process is riddled with uncertainty (Ezra 1980). Sponsors respond to that uncertainty by making key assumptions about the size of their future pension obligations, the likelihood that benefits will need to be paid, and the portion of their future obligations that should be currently funded in order to have all of the necessary assets set aside to pay for the benefits by the time their employees retire. As workers near retirement, the future becomes more 
certain and assumptions are less critical. Once benefit levels are certain (or even as they near certainty), it is generally too late to quickly recover from a significant deficit in pension funds. Plan sponsors who set assumptions that turn out to be too optimistic will not have saved enough to pay their retirees' benefits from the savings in their pension funds. In order to make up the shortfalls, sponsors need to increase their annual contributions and/or consume pension fund assets that were intended for future retirement payments.

In the effort to avoid a funding shortfall, actuaries utilize two sets of assumptions to calculate pension liabilities and contribution requirements (American Academy of Actuaries 2004). Demographic assumptions are used to predict employee turnover and the number of workers who will ultimately qualify for pension benefits. Demographic assumptions include mortality rates, turnover rates, disability rates, and termination rates. Economic assumptions are used to forecast growth in the future value of pension benefits and to calculate the present value of those future payments. Economic assumptions include inflation rates, discount rates, and salary growth rates.

Actuaries use those assumptions to calculate pension liabilities and contribution requirements. Pension liabilities represent the present value of future benefit payments that have already been earned by employees. The pension liability for a plan with multiple participants is calculated as the sum of the individual liabilities for each qualified plan participant. Contribution requirements represent the actuarially determined amount of money that needs to be deposited each year into a pension fund and held in trust for future benefit payments.

Liabilities and contribution requirements are highly related. One portion of contribution requirements is the amount of money needed to cover the benefits that are earned in the current year (the normal cost (NC)). Pension liabilities, or the actuarially accrued liability (AAL), are the accumulation of normal costs for all the completed years of employees' service.

When a pension fund does not hold sufficient assets to cover its AAL, the plan recognizes an unfunded actuarial accrued liability (UAAL). Plans with UAALs are not expected to make up the shortfalls in a single year. Rather, they are allowed to finance the unfunded liability over a period of time (an amortization period). The amortized UAAL is the second portion of a sponsor's contribution requirement.

The combination of the normal cost and the amortized UAAL is usually referred to as the annual required contribution or ARC. It is often expressed as a percent of a pension system's 
covered payroll. New accounting standards refer to this calculation as the actuarially determined contribution (GASB 2012), though we retain the common ARC terminology in this paper.

The actuarial process assumes that conditions will change and assumptions will need to be revised. Actuaries, therefore, conduct periodic reviews of plan conditions, usually no less frequently than every five years, and test whether the actuarial assumptions are consistent with actual experience (GFOA 2009; Peng 2008). Actuaries regularly suggest changes to actuarial inputs based on (1) changes in professional standards (e.g., revised mortality tables), (2) changes in governmental accounting standards, and (3) whether actual conditions deviate from actuarial assumptions. Actuaries may suggest revisions, but boards of trustees and sponsoring governments’ governing bodies are responsible to review those suggestions and determine whether to revise actuarial inputs.

Academic studies suggest that decision makers use the discretion allowed by accounting standards to adopt actuarial inputs that postpone pension costs in order to spend more on current government services (Johnson 1997; Marks, Raman and Wilson 1988). The incentive to adopt favorable actuarial inputs is thought to be particularly strong in governments under budgetary stress (Chaney, Copley, and Stone 2002; Giertz and Papke 2007; Mitchell and Hsin 1997; Schneider and Damanpour 2002). Others suggest that the selection of actuarial inputs is affected by political pressure (Romano 1993). For example, Levine, Rubin and Wolohojian (1981) found that when the City of Oakland was under fiscal stress in the 1970s, their pension system increased its amortization period from 14 years to 40 years. Also, Eaton and Nofsinger (2004) found that governments under political pressure and fiscal constraints decreased their salary growth rate assumptions, increased their amortization periods, and increased their discount rates. Chaney, Copley and Stone (2002) found that states with balanced budget requirements increased their discount rates when facing fiscal stress.

In addition, anecdotal evidence supports claims that actuarial assumptions are sometimes manipulated in order to improve short-term fiscal and political conditions. In response to a fiscal crisis in the early 1990s, the State of New York changed their method of allocating the costs of pension obligations (Bentley 2009). New York's public employees challenged that decision and the court ruled against the state, deciding that the change was not intended "to protect the retirement funds earned by members and beneficiaries of the system but to deal with the budget crises being experienced by governmental entities in New York State” (McDermott v. Regan 
1993, 359). In 2009, the City of Philadelphia announced a plan to reduce its ARC by $\$ 170$ million by increasing its amortization period from 20 to 40 years (Lucey 2009). And, in 2013, a member of the Montana Board of Investments cited significant gubernatorial pressure as a reason why the Board reversed its decision to reduce the Montana Public Employees Retirement Systems' discount rate (Johnson 2013).

\section{Actual Variation in Pension Assumptions}

While there are strong modal norms in the selection of actuarial inputs by public pension systems, there is still a fair amount of variation around those norms. In this paper we focus on four actuarial inputs: discount rates, salary growth rates, cost methods, and mortality tables. In this section, we describe each of those actuarial inputs and summarize their variation in state and large locally-administered pension systems. We identify the distribution of actuarial inputs in U.S. pension systems by using the Center for Retirement Research at Boston College's Public Plans Database (PPD) (Public Plans Database 2001-2013). The PPD provides information on 150 state and local pension plans from 2001 to 2013 and includes more than 85 percent of state and local pension assets and membership.

Tables 1 and 2 demonstrate the variation in actuarial inputs in public pensions. Two qualifications are important to note. First, the range of values in Table 1 excludes the outliers at the minimum and maximum positions in order to more accurately present the range of typical values in practice. Second, mortality tables are not reported in the PPD and are therefore not shown in Tables 1 or 2.

Discount rates ${ }^{1}$ are used to calculate the present value of future benefits. Larger discount rates lead to lower liabilities, higher funding ratios (i.e., the ratio of asset holdings to liabilities), and lower contribution requirements. As reported in Table 1, the median discount rate is 8 percent and the range of typical discount rates is between 6 and 8.75 percent.

Salary growth rates are used to predict the geometric growth in employee salaries. Higher salary growth rates increase the predicted value of final average salaries. This is expected to lead to higher pension liabilities, lower funding ratios, and higher contribution

\footnotetext{
${ }^{1}$ The inflation rate is a component in both the discount rate and the salary growth rate, so changing the inflation rate affects both rates.
} 
requirements. Table 1 shows that the typical range in salary growth rate assumptions is 3 to 8 percent and the median assumption is 6 percent.

Actuarial cost methods are used to determine the normal cost for each year of employee service. Cost methods can allocate the benefits over employees' service periods, such as with Projected Unit Credit (PUC), or allocate the costs over service periods, such as with Entry Age Normal (EAN) and Aggregate Cost (AGG) (Peng 2008). This distinction is technical, but the effect is that cost-prorated methods (such as EAN) tend to have larger normal costs in early years of employee service, while benefit-prorated methods (such as PUC) tend to produce progressively increasing normal costs. As shown in Table 2, 72 percent of plans use EAN, 13 percent use PUC, eight percent use AGG, and seven percent use other methods (such as Frozen Initial Liability).

Mortality tables (not shown in Tables 1 or 2 because they are not reported in the PPD) are used to project the likelihood that employees will remain in the plan long enough to receive their full benefits and to evaluate life expectancy after retirement. With an aging population and the retirement of baby boomers, there are concerns that some public pension systems calculate their liabilities based on outdated mortality tables (Munnell, Aubry and Cafarelli 2015). Because life expectancies continue to increase, the most recent mortality tables tend to increase the expectation that employees will survive long enough to receive their retirement benefits and then receive more benefit payments after retirement. Munnell, Aubry and Cafarelli (2015) have examined the effect of mortality assumptions on the funded ratios of public plans. They found that updating the mortality tables would reduce aggregated funded ratios by six percent.

\section{Simulation Model}

In order to identify the marginal effects of changes to actuarial inputs on funding ratios and contribution requirements, we simulated a typical public pension system. Simulations have been used in prior research on pension management. For example, Kingsland and Gruber (1982) used a simulation model to examine the impacts of investment policies on the financial condition of pension systems. Fehr, Kallweit and Kindermann (2012) simulated the macroeconomic, welfare and efficiency consequences of increasing the normal retirement age in the German national pension system. To our knowledge, however, no similar work has been done to 
systematically examine the effects of changes in various actuarial inputs. This study fills that gap.

Since actuarial inputs have deterministic effects on pension liabilities and contribution requirements, it is possible to simulate those relationships under hypothetical conditions with a reasonable level of external validity. Also, by isolating the deterministic effects in a controlled environment, there is no need for statistical analysis to determine whether or not differences are the result of random error (i.e., internal validity).

We use the median conditions of actual pension systems in the Public Plans Database (PPD) in our baseline simulation. We call this baseline simulation the "median plan.” The conditions for the "median plan" are listed in the note section of Table 3. We follow Winklevoss's (1993) method $^{2}$ to calculate normal costs and AALs, and perform our calculations in Microsoft Excel with Visual Basic coding. We use those calculations to identify the funding ratio (assets/liabilities $\times 100 \%)$ and contribution rates [(normal costs + UAAL amortization costs)/payroll] for the median plan. The rest of the paper uses the term ARC to refer to the contribution rate calculation. We then calculate the funding ratio and ARC as the actuarial input values are changed from the median condition.

We conducted two tests of the simulation's external validity. In the first test, we compared the median plan's simulated normal cost and AAL with the median and mean values of the normal costs and AALs observed in the actual plans within the PPD (see Table 3). In the second test, we simulated the normal costs and AALs for each plan in the PPD, using their reported actuarial inputs, and compared our simulated results with the observed normal costs and AALs reported in the PPD (see Figure 1).

The results of our external validity tests show that the simulation calculates normal costs and AALs that closely match actual observations with some minor deviations. Figure 1 shows that the variances center around zero and that 75.6 percent of the simulated normal costs are within +/- five percent of payroll from the observed data, while 71.6 percent of the simulated AALs are within two times of payroll from the observed data. As shown in Table 3 and Figure 1, both the simulated normal costs and AALs are slightly under-estimated. This is expected

\footnotetext{
${ }^{2}$ Normal costs are calculated using formula (6.21) on page 89 in Winklevoss (1993). Actuarial liabilities are calculated using formulas (5.6)-(5.9) on pages 74-75 (Winklevoss, 1993). Cost methods follow Table 10-1 on page 143 (Winklevoss, 1993). UAAL amortization costs are calculated using formula (7.8) on page 101 (Winklevoss, 1993). Termination costs are calculated using formula (8.2) on page 115 (Winklevoss, 1993).
} 
since the simulation only considers core pension benefits (e.g., no retirement incentives, disability benefits, COLA benefits, or surviving spouse benefits) and does not consider that senior employees may be in a more generous tier of retirement benefits than the conditions reported in the PPD. The results of this comparison provide reasonable confidence that our simulation is externally valid for a typical plan, but suggest caution before applying the baseline simulation to individual plans.

To expand on the median plan, we created a "young” plan and a “mature” plan. The age distribution of the young plan is skewed to the right (skewness is approximately .7) and the age distribution of the mature plan is skewed to the left (skewness is approximately -.7). We then calculated the effects of marginal changes in actuarial inputs on the funding ratios and ARCs of the young and mature plans. The young and mature plans allow us to examine the effect of demographic profiles on the marginal effects of actuarial inputs.

The last step was to simulate the effect of a plan's funding condition (i.e., funding ratio) on the marginal effects of actuarial inputs. This was done by creating another plan that is identical to the median plan but has a 70 percent funding ratio, and another plan that has a 100 percent funding ratio. We then calculate the effects of marginal changes in actuarial inputs on the funding ratios and ARCs at both of those funding levels. We now turn to the results of the simulations.

\section{Results}

In this section, we discuss the marginal effects of changes to discount rates, salary growth rate assumptions, cost methods, and mortality tables.

The results of marginal changes on funding ratios are shown in Table 4 and the results on ARCs are presented in Table 5. The tables show the marginal effects on the median plan in column 1. They present the effects on a plan with a younger demographic in column 2 and a mature demographic in column 3. The only difference between columns 1,2 , and 3 is the age demographic of their participants; assets in each of those columns are fixed to the same level, so that the funding level is set to the median condition of 85.4 percent. Column 4 provides information on the median plan when its asset level is fixed to 70 percent of its liability, and column 5 fixes the assets to 100 percent of its liability. The rest of this section provides analysis on each of the actuarial inputs. 
What Are the Marginal and Lagged Effects of Changing the Discount Rate?

We changed the discount rate by .25 percentage-point increments to measure its effect on funding ratios (Table 4, panel A) and ARCs (Table 5, panel A). As expected, we find that funding ratios and ARCs are both highly sensitive to changes in the discount rate. However, the marginal effect is smaller than the " $4 \%$ rule of thumb"” used by Chaney, Copley, and Stone (2002). ${ }^{3}$ In the median plan (column 1), a one-percentage point increase in the discount rate increases the funding ratio by an average of 9.75 percentage points, and reduces the ARC by an average of 8.15 percentage points. This shows the significant incentive for plan sponsors to select and keep a high discount rate. It also illustrates why plan sponsors often push back on efforts to adopt riskless rates of return (closer to 5 or 6 percent) in order to preserve budgetary resources.

We also found that the influence of the discount rate is affected by a plan's demographic profile and asset level, as shown in columns 2-5.

The discount rate has a larger effect on a younger plan than a more mature one. ${ }^{4}$ The heightened effect of younger plans is because the plan's active employees are further away from their retirement age and the effects of discounting are increased by longer time period. Because younger plans are more sensitive to discount rate changes, there is a clear incentive for younger plans to select and retain higher discount rates.

The effect of changing the discount rate is also larger in a plan that is well funded than in one that is less well funded. A well-funded plan is more sensitive to discount rate changes because changing the discount rate affects the plan's liability, and the liability is in the denominator of the funding ratio calculation. Ratio calculations are more sensitive to denominator changes when their numerators are larger. ${ }^{5}$ The amplified effect of the discount rate when the funding ratio is higher is also found in the ARC. This finding suggests that well-

\footnotetext{
${ }^{3}$ The " $4 \%$ rule of thumb" suggests that every 25 basis point change in the assumed discount rate has a 4 percent effect on the pension benefit obligation. According to this rule, when the median plan reduces the discount rate from 8 percent to 7.75 percent, the funding ratio should reduce to 82.12 percent (85.4/104). However, according to the simulation, we see that the funding ratio only reduces to 82.86 percent because of the 25 basis point change in the discount rate.

${ }^{4}$ Similar results have been found in prior studies (GAO 2014; Sielman 2015).

${ }^{5}$ For example, if a plan is 100 percent funded with $\$ 100$ assets and $\$ 100$ liabilities, a 10 percentage point decrease in the liability increases the funding ratio by 11.11 percentage points $(\$ 100 / \$ 100-\$ 100 / \$ 90) \times 100 \%$. And, if a plan is $50 \%$ funded with $\$ 50$ assets and $\$ 100$ liabilities, a $10 \%$ decrease in the liability only increases the funding ratio by 5.56 percentage points $(\$ 50 / \$ 100-\$ 50 / \$ 90) \times 100 \%$.
} 
funded plans actually have more to lose by reducing their discount rates and stronger incentives to increase their discount rates.

More importantly, changing the discount rate also has significant long-term effects on both funding ratios and ARCs. To illustrate, we examine the long-term effects of a pension system that changes its discount rate but does not experience different investment returns.

We start with the baseline condition in year 1 . The discount rate is set to 8 percent and the assets are set to 85.4 percent of the liability. Under those conditions, the ARC is 17.35 percent. Then we recalculated the funding ratio and ARC by both increasing the discount rate to 9 percent and decreasing it to 7 percent, without changing the asset values.

While holding annual returns constant at an 8 percent average annual return with a standard deviation of 7.80 percent, we simulate how the funding ratios and ARCs of the three discount rate conditions change over time. To simulate the investment returns, we follow Stalebrink, Kriz and Guo’s (2010) approach and simulate an investment portfolio ${ }^{6}$ for the median plan over 10,000 runs.

Figures 2 and 3 show the simulated funding ratios and ARCs over a 20-year period for all three of the discount rate conditions. In the first year, when the discount rate is lowered to 7 percent, the funding ratio drops to 75.55 percent and the ARC increases to 25.39 percent of payroll (as also shown in Tables 4 and 5). In the long run, however, the funding ratio gradually increases to over 100 percent and its ARC decreases to around 10 percent at the end of the $20^{\text {th }}$ year. In contrast, when the discount rate is raised to 9 percent, the funding ratio immediately rises to 96.09 percent and the ARC is lower than 10 percent in the first year, but the funding ratio decreases to lower than 85 percent and the ARC eventually increases to more than 15 percent by the $20^{\text {th }}$ year. Figures 2 and 3 show that using a higher discount rate reduces liabilities and costs in the short-term but postpones the costs to the future. Figure 2 also shows that, if the median plan lowers its discount rate by one percent but investment returns and funding policies do not change, it may take about seven years before the funding ratio returns to its previous level of 85.4 percent and its ARC may take about 15 years to return to its original level.

\footnotetext{
${ }^{6}$ Stalebrink, Kriz and Guo’s (2010) approach simulates an asset portfolio of 30\% equities, 30\% fixed income, 20\% real estate, $10 \%$ cash and $10 \%$ alternatives. We simulate 10,000 runs of investment returns and then calculate 20 year trends based on the mean annual returns. We use 5-year asset smoothing in the simulation, which is used by most public pension plans. If no asset smoothing is used, the simulated results are consistent. We do not assume mean reversion.
} 
What Is the Marginal Effect of Changing the Salary Growth Rate and How Does It Interact with Different Cost Methods?

Panel B of Tables 4 and 5 illustrates the effect of changing the salary growth rate assumption. Prior studies have produced inconsistent estimates of the relationship between financial condition and salary growth rate. We find that the salary growth rate has a larger influence on the ARC than on the funding ratio. Under median conditions, a one-percentage point increase in the salary growth rate reduces the average funding ratio by 2.13 percentage points and increases the ARC by 4.77 percentage points.

Mitchell and Smith (1994) found that discount rates and salary growth rates have similar effects on required contributions when they used the dollar amount of the required contributions as the dependent variable. In our model, we compare the ARCs with payrolls and find that discount rates have a greater effect than the salary growth rates. We also find that this effect depends on the cost method and plans' demographic profiles, and so we examined this interactive relationship more closely.

Figure 4 illustrates the interactive effect of changes to salary growth rates under different cost methods and demographic profiles. Increasing the salary growth rate assumption, regardless of cost methods, leads to lower funding ratios and higher contribution requirements, though the magnitude of those changes is affected by both the system's demographic profile and the cost method. This may be one explanation for inconsistent findings in prior studies. For example, the graphs on the top row of Figure 4 show that funding ratios are more sensitive to changes in the salary growth rate under the PUC cost method than under the EAN cost method. When the salary growth rate increases from 4.5 percent to 7 percent, the funding ratio for the young plan reduces by less than 5 percent when using the EAN method but reduces by more than 10 percent under the PUC method.

Another interactive effect of demographic conditions is that both the funding ratios and ARCs for the mature plan change at a steeper rate than for the young plan. This is because there is less time to discount the effect of the assumed salary increase and because of the larger unfunded liability that is created by allocating the new normal cost over the entire career of employees who are near retirement. This means that plans with a large number of participants that are nearing retirement have a stronger incentive to lower their salary growth rate assumptions. To illustrate, if a plan with a mature demographic reduces its salary growth rate 
assumption from 6.50 percent to 5.75 percent, it decreases its ARC from 23.33 percent to 18.24 percent, as shown in the third column in Table 5. With a median payroll (\$2.4 billion), that amounts to a budgetary savings of $\$ 122.16$ million.

What Is the Marginal Effect of Changing the Actuarial Cost Method?

PUC and EAN are the most commonly used actuarial cost methods. In the prior literature, only one study (Giertz and Papke 2007) controls for the use of different cost methods when comparing funding ratios. In our simulation, we find that the choice of cost methods has a relatively small marginal effect on pension costs under median conditions, especially in comparison to the much larger effects from discount rates and salary growth rates. As shown in Panel C of Tables 4 and 5, the median plan's funding ratio decreases by 6.71 percentage points when it changes from the PUC to EAN method and its ARC increases by 0.93 percentage points.

The new GASB standards require that plans report their funding ratios using the EAN method. For most plans currently using PUC, this will likely have a small, but nontrivial, negative effect on their funding ratios (reducing them by about 4.5 to 6.5 percent). The effect on the contribution rate is more interesting. Plans with a younger demographic will likely experience a slight increase in their ARCs (about 1.92 percent), and plans with mature demographics will have a lower ARC (about 1.20 percent). This is because EAN accumulates an employee's normal costs faster in the early years of service, while PUC accumulates normal costs faster in later years. PUC accelerates the accumulation of AAL in the last 20 years before retirement. Both methods reach the same AAL at retirement. The margin effect of changing between EAN and PUC is not large and, therefore, it is unlikely that plans switch their cost method to manipulate their contribution rates. However, as demonstrated in Figure 4, a more important effect of changing actuarial cost methods is the result of the interactive effect of cost methods with salary growth rate assumptions.

\section{What Is the Marginal Effect of Changing the Mortality Rate Assumption?}

One prior study found that updating pension systems to the most recent mortality table (called RP-2014) would reduce the funded ratios for public pension plans by six percent (Munnell, Aubry and Cafarelli 2015). We found similar and slightly larger effects in our simulation. As shown in Panel D of Tables 4 and 5, updating the median plan's mortality table 
from RP-2000 to the revised version of RP-2000 that includes a 10-year projection using scale AA reduced the funding ratio by 2.26 percentage points and increased the ARC by 1.49 percentage points. Updating the mortality table from RP-2000 with the 10 -year projection to RP-2014 reduces the funding ratio by 4.74 percentage points and increases the ARC by 3.41 percentage points. This demonstrates why governing boards of some pension systems may delay updating their mortality tables in order to prop up their funding ratios and to avoid adopting a higher ARC. Given the relatively larger increase that occurs when selecting the more recent mortality table, we should not be surprised by delays in adopting newer tables. The decision to update a plan under median conditions from RP-2000 to RP-2014 means reducing the funding ratio by around six to eight percentage points. The effect is amplified in plans that are better funded and for younger plans. The younger plan also experiences a greater increase in its ARC as a result of updating its mortality table compared to the plan with a mature age distribution.

The mortality table affects pension costs and liabilities in three ways. First, before retirement, the mortality table is used to predict the probability that workers will "survive" to the normal retirement age. If employees fail to accumulate sufficient service years to qualify for retirement benefits, their benefits will be eliminated or reduced. Second, updating the mortality rate increases the assumed life expectancy. With longer life expectancies, benefit annuities are paid over longer time periods, so projected pension liabilities increase. The third reason is specific to the changes in individual mortality tables. When RP-2014 is compared with RP2000, the mortality improvement rate (i.e., the difference in mortality rates from one mortality table to another within the same age group) across most the age groups is approximately 2 percent. However, the improvement is larger for age groups around 40 (a mortality improvement rate of 3 percent) and 65 (a mortality improvement rate of 3.3 percent). If a plan has more employees or retirees in the 40 and 65 age groups, the marginal effect from updating their mortality table will be larger.

\section{Conclusion}

The financial condition of public pensions is a key concern for many state and local governments. Policy debates are significantly affected by the valuation of pension liabilities and the budgetary burden of pensions’ contribution requirements. In this paper, we use a simulation research design to examine how the selection of actuarial input values affects the size of pension 
liabilities (presented as funding ratios) and the contribution requirements (presented as annual required contribution as a share of payroll). The simulation demonstrates the following:

1. Discount rates, salary growth rates, cost methods, and mortality tables all influence funding ratios and contribution requirements. Without adjusting or considering these effects, comparisons of funding ratios across pension systems will produce biased results.

2. The discount rate assumption is the most influential actuarial input on both funding ratios and contribution requirements. We show that a plan can postpone required contributions by raising its discount rate assumption, but its funding condition deteriorates in the long run. In contrast, if a plan reduces its discount rate by 1 percentage point, and its investment returns continue at the level that was previously assumed, it will take approximately seven years for the funding ratio to return to its original level and an even longer time period for the ARC to return to its original level (though the exact length of time depends on investment returns and the baseline discount rate assumption).

3. The effects of actuarial inputs greatly depend on plan characteristics such as demographic profiles and asset levels, as well as interactions with other actuarial inputs. Because of the interactive effects, it is difficult to standardize funding ratios or pension obligations by only controlling for a single actuarial input. With better data on plan characteristics (such as information on mortality tables and age distributions), simulations could be used to standardize pension liabilities. In the absence of this information, improved consistency in financial reporting (such as requiring a single cost method) is an effective way to facilitate better comparisons of financial conditions across pension plans.

The influence of actuarial inputs demonstrates that there are many ways to influence the reported condition of public pension systems without actually changing the fundamental financial health of the plan. Many actuarial input changes do not receive significant outside review. Governments and citizen groups may benefit from independent reviews of the actuarial inputs used to value their pension liabilities in order to ensure that trustees are selecting actuarial 
inputs that do not put future taxpayers at risk.

There are several limitations in this study that warrant further research. For one, this study uses a variety of simplifications. For example, the simulation is limited to four actuarial inputs, three asset levels, three demographic conditions, a single benefit plan, and beneficiaries are limited to employees. Furthermore, due to space constraints, we look at only a few interactive effects. Future research should expand an examination into interactive effects, economic and demographic conditions, benefits provisions, and additional actuarial inputs.

Another limitation is that simulation is based on median conditions. This means that the simulated plan may reflect a typical plan but not provide sufficient insight into specific pension systems. Further work to model actual pension systems will help researchers understand the political incentives and constraints facing actual governments and pension managers.

Finally, this paper has treated funding ratios and contribution requirements as equivalent measures. Much of the popular discussion on the financial health of pension systems focuses on the funding ratio (or a similar stock measure). However, while funding ratios and contribution requirements are associated, they are not the same. Whether pension systems are 72 percent or 79 percent funded, for example, is unlikely to influence the political environment or the opinions of capital market participants. However, a small increase in the contribution rate can create significant budgetary pressure or further strain governments in fiscal distress. Further research is needed to understand how public officials and stakeholders view the relative importance of funding ratios and contribution requirements. 


\section{References}

American Academy of Actuaries. 2004. "Fundamentals of Current Pension Funding and Accounting For Private Sector Pension Plans: An Analysis by the Pension Committee of the American Academy of Actuaries.” Washington, DC. Available at: http://www.actuary.org/pdf/pension/fundamentals_0704.pdf

Bentley, Andria L. 2009. “The New York State Comptroller as Sole Trustee of the Common Retirement Fund: A Constitutional Guarantee?” Albany Law Review 72(3): 761-788.

Biggs, Andrew G. 2012. “Public Sector Pensions: How Well Funded Are They, Really?” State Budget Solutions. American Enterprise Institute: Washington, DC. Available at: https://www.aei.org/publication/public-sector-pensions-how-well-funded-are-they-really/

Chaney, Barbara A., Paul A. Copley, and Mary S. Stone. 2002. “The Effect of Fiscal Stress and Balanced Budget Requirements on the Funding and Measurement of State Pension Obligations.” Journal of Accounting and Public Policy 21(4-5): 287-313.

Coggburn, Jerrell D. and Richard C. Kearney. 2010. "Trouble Keeping Promises? An Analysis of Underfunding in State Retiree Benefits.” Public Administration Review 70(1): 97-108.

Dulebohn, James H. 1995. “A Longitudinal and Comparative Analysis of the Funded Status of State and Local Public Pension Plans.” Public Budgeting \& Finance 15(2):52-72.

Eaton, Tim V. and John R. Nofsinger. 2004. "The Effect of Financial Constraints and Political Pressure on the Management of Public Pension Plans.” Journal of Accounting and Public Policy 23(3): 161-189.

Ezra, D. Don. 1980. “How Actuaries Determine the Unfunded Pension Liability.” Financial Analysts Journal 36(4): 43-50.

Employees’ Retirement System of Georgia (Georgia ERS). 2013. Report of the Actuary on The Valuation. Atlanta, GA. Available at: http://www.ers.ga.gov/plans/ers/ersactuarial.html.

Fehr, Hans, Manuel Kallweit, and Fabian Kindermann. 2012. "Pension Reform with Variable Retirement Age: A Simulation Analysis for Germany.” Journal of Pension Economics and Finance 11(3): 389-417.

Giertz, J. Fred and Leslie E. Papke. 2007. "Public Pension Plans: Myths and Realities for State Budgets.” National Tax Journal 60(2): 305-324.

Government Accountability Office (GAO). 2014. Pension Plan Valuation: Views on Using Multiple Measures to Offer a More Complete Financial Picture. Washington, DC. Available at: http://www.gao.gov/products/GAO-14-264 
Governmental Accounting Standards Board (GASB). 2012. Statement No. 68 of the Governmental Accounting Standards Board: Accounting and Financial Reporting for Pensions. Norwalk, CT.

Government Finance Officers Association (GFOA). 2009. "Sustainable Funding Practices of Defined Benefit Pension Plans.” Chicago, IL.

Johnson, Charles S. 2013. "Board Member Calls for Lower Rate of Return on Pension Investments.” (October 21). Billings Gazette. Billings, MT.

Johnson, Richard W. 1997. "Pension Underfunding and Liberal Retirement Benefits among State and Local Government Workers.” National Tax Journal 50(1): 113-142.

Kingsland, Louis and Martin J. Gruber. 1982. "Projecting the Financial Condition of a Pension Plan Using Simulation Analysis.” The Journal of Finance 37(2): 577-584.

Levine, Charles Howard, Irene S. Rubin, and George G. Wolohojian. 1981. The Politics of Retrenchment: How Local Governments Manage Fiscal Stress. Beverly Hills, CA: Sage Publications.

Lucey, Catherine. 2009. “Nutter Announces Pension Saving Plan.” (February 13). Philly.com. Philadelphia, PA. Available at: http://www.philly.com/philly/blogs/cityhall/Nutter_Announces_Pension_Savings_Plan.ht $\underline{\mathrm{ml}}$

Marks, Barry R., K. K. Raman, and Earl R. Wilson. 1988. “Toward Understanding the Determinants of Pension Underfunding in the Public Sector.” Journal of Accounting and Public Policy 7(3): 157-183.

McDermott v. Regan, 624 NE 2d 985. (NY: Court of Appeals 1993).

Mitchell, Olivia S. and Ping Lung Hsin. 1997. "Public Pension Governance and Performance.” In The Economics of Pensions: Principles, Policies and International Experience, edited by Salvador Valdes-Prieto, 92-126. Cambridge, MA: Cambridge University Press.

Mitchell, Olivia S. and Robert M. Smith. 1994. "Pension Funding in the Public Sector.” The Review of Economics and Statistics 76(2): 278-290.

Moody’s Investor Service. 2013. Adjusted Pension Liability Medians for US States: New Measures Highlight Varying Affordability. New York, NY. Available at: www.ncsl.org/documents/summit/summit2013/online-resources/Moody-AdjustedPension-Liability-Medians.pdf

Munnell, Alicia H., Jean-Pierre Aubry, and Mark Cafarelli. 2015. "How Will Longer Lifespans Affect State and Local Pension Funding?” State and Local Plans Issue in Brief 43. Chestnut Hill, MA: Center for Retirement Research at Boston College. 
National Association of State Retirement Administrators (NASRA). 2015. "Public Pension Plan Investment Return Assumptions.” Issue Brief. Available at: http://www.nasra.org/files/Issue\%20Briefs/NASRAInvReturnAssumptBrief.pdf

Novy-Marx, Robert and Josh Rauh. 2011. "Public Pension Promises: How Big Are They and What Are They Worth?” The Journal of Finance 66(4):1211-1249.

Peng, Jun. 2008. State and Local Pension Fund Management. Boca Raton, FL: Taylor \& Francis Group.

Public Plans Database. 2001-2011. Center for Retirement Research at Boston College, Center for State and Local Government Excellence, and National Association of State Retirement Administrators.

Rich, Keving T. and Jean X. Zhang. 2015. "Unfunded Public Pension Liabilities and Local Citizen Oversight.” Accounting Horizons 29(1): 23-39.

Romano, Roberta. 1993. "Public Pension Fund Activism in Corporate Governance Reconsidered.” Columbia Law Review 93(4): 795-853.

St. Clair, Travis. 2013. "The Impact of Budget Stabilization Funds on State Pension Contributions.” Public Budgeting \& Finance 33(3): 55-74.

Schneider, Marguerita and Fariborz Damanpour. 2002. "Public Choice Economics and Public Pension Plan Funding: An Empirical Test.” Administration \& Society 34(1): 57-86.

Sielman, Rebecca A. 2015. Milliman 2015 Public Pension Funding Study. Seattle, WA. Available at: http://www.milliman.com/uploadedFiles/insight/Periodicals/ppfs/ppfs2015.pdf

Society of Actuaries (SOA). 2003. SOA Pension Plan Turnover Study. Schaumburg, IL. Available at: https://www.soa.org/experience-studies/2000-2004/research-2003-soapension-plan-turnover-study/

Stalebrink, Odd, Kenneth Kriz, and Weiyu Guo. 2010. "Prudent Public Sector Investing and Modern Portfolio Theory: An Examination of Public Sector Defined Benefit Pension Plans.” Public Budgeting \& Finance 30(4): 28-46.

Teachers' Retirement System of the State of Illinois (Illinois TRS). 2013. Comprehensive Annual Financial Report. Springfield, IL. Available at: http://trs.illinois.gov/pubs/cafr/FY2013/fy13.pdf

Thom, Michael. 2013. "All of the Above: How Fiscal, Political, and Workforce Traits Affect Pension Funding.” State and Local Government Review 45(3): 163-171. 
Triest, Robert K. and Bo Zhao. 2013. The Role of Economic, Fiscal, and Financial Shocks in the Evolution of Public Sector Pension Funding. Working Paper No. 13-26. Boston, MA:

Federal Reserve Bank of Boston. Available at: http://ssrn.com/abstract=2433796

Winklevoss, Howard E. 1993. Pension Mathematics with Numerical Illustrations. Philadelphia, PA: Pension Research Council. 
Table 1. Variations in Actuarial Assumptions

\begin{tabular}{|l|c|c|c|c|c|}
\hline & $\begin{array}{c}1^{\text {st }} \\
\text { percentile }\end{array}$ & $\begin{array}{c}25^{\text {th }} \\
\text { percentile }\end{array}$ & $\begin{array}{c}50^{\text {th }} \\
\text { percentile }\end{array}$ & $\begin{array}{c}75^{\text {th }} \\
\text { percentile }\end{array}$ & $\begin{array}{c}99^{\text {th }} \\
\text { percentile }\end{array}$ \\
\hline Discount rate & $6 \%$ & $7.75 \%$ & $8 \%$ & $8.25 \%$ & $8.75 \%$ \\
\hline Salary growth rate & $3.1 \%$ & $5 \%$ & $5.68 \%$ & $6.25 \%$ & $8 \%$ \\
\hline
\end{tabular}

Table 2. Variations in Using Actuarial Cost Methods

\begin{tabular}{|l|c|}
\hline & Incidence in Public Pension Plans \\
\hline Entry Age Normal (EAN) & $72 \%$ \\
\hline Projected Unit Credit (PUC) & $13 \%$ \\
\hline Aggregate Cost (AGG) & $8 \%$ \\
\hline Other methods (e.g., frozen initial liability) & $7 \%$ \\
\hline
\end{tabular}

Table 3. Comparing the Simulation Results to Observed Conditions in Actual Public Pensions

\begin{tabular}{|l|c|c|c|}
\hline & \multirow{2}{*}{\begin{tabular}{c} 
Test results when \\
assumptions are set to the \\
\cline { 3 - 4 }
\end{tabular}} & \multicolumn{2}{|c|}{ Observed Conditions in the PPD data } \\
\cline { 3 - 4 } & $\begin{array}{c}\text { Medianditions the PPD } \\
\text { (see note) }\end{array}$ & Median & Mean \\
\hline Normal Cost & $10.35 \%$ of payroll & $12.18 \%$ of payroll & $13.53 \%$ of payroll \\
\hline $\begin{array}{l}\text { Actuarially } \\
\text { Accrued Liability } \\
\text { (AAL) }\end{array}$ & 5.35 of payroll & 5.44 of payroll & 6.56 of payroll \\
\hline
\end{tabular}

Note: The simulated results are based on the typical actuarial inputs (median values) from the PPD:

- $\quad$ Employees begin work when they are 30 years old and retire at 65;

- $\quad$ Retirement benefits are paid as life annuities;

- A 5-year vesting period;

- $\quad$ Average age of active employees $=45$;

- $\quad$ Benefit multiplier = 2\%;

- $\quad$ Discount rate = 8\%;

- $\quad$ Salary growth rate $=5.68 \%$;

- $\quad$ Amortization period = 29 years;

- $\quad$ The mortality table is the RP-2000 with 10 year projection;

- $\quad$ Employee turnover rates follow 2003 SOA Pension Plan Turnover Study;

The cost method is Entry Age Normal. 
Table 4. Effect of Actuarial Input Changes on Funding Ratios

\begin{tabular}{|c|c|c|c|c|c|}
\hline \multirow[b]{2}{*}{ Actuarial Input } & \multicolumn{3}{|c|}{$\begin{array}{l}\text { Assets in median condition are set to } \\
\text { an } 85.4 \% \text { funding ratio }\end{array}$} & \multirow{2}{*}{$\begin{array}{c}\text { Assets in } \\
\text { median } \\
\text { condition } \\
\text { set to a } \\
70 \% \\
\text { funding } \\
\text { ratio } \\
(4)\end{array}$} & \multirow{2}{*}{$\begin{array}{c}\text { Assets in } \\
\text { median } \\
\text { conditio } \\
\text { n set to a } \\
100 \% \\
\text { funding } \\
\text { ratio } \\
\text { (5) }\end{array}$} \\
\hline & $\begin{array}{l}\text { Average age } \\
\text { for Active } \\
\text { participants } \\
\text { is } 45 \\
\text { (1) }\end{array}$ & $\begin{array}{c}\text { Active } \\
\text { participant } \\
\text { ages are } \\
\text { skewed } \\
\text { younger } \\
(2)\end{array}$ & $\begin{array}{c}\text { Active } \\
\text { participant } \\
\text { ages are } \\
\text { skewed } \\
\text { mature } \\
\text { (3) }\end{array}$ & & \\
\hline \multicolumn{6}{|c|}{ Panel A: Discount Rates (median observed value is $8 \%$ ) } \\
\hline 8.75 & $93.34 \%$ & $93.77 \%$ & $92.45 \%$ & $76.50 \%$ & $109.29 \%$ \\
\hline 8.50 & $90.64 \%$ & $90.92 \%$ & $90.06 \%$ & $74.29 \%$ & $106.13 \%$ \\
\hline 8.25 & $87.99 \%$ & $88.13 \%$ & $87.71 \%$ & $72.12 \%$ & $103.04 \%$ \\
\hline 8.00 & $85.40 \%$ & $85.40 \%$ & $85.40 \%$ & $70.00 \%$ & $100.00 \%$ \\
\hline 7.75 & $82.86 \%$ & $82.73 \%$ & $83.13 \%$ & $67.92 \%$ & $97.03 \%$ \\
\hline 7.50 & $80.37 \%$ & $80.12 \%$ & $80.90 \%$ & $65.88 \%$ & $94.11 \%$ \\
\hline 7.25 & $77.94 \%$ & $77.57 \%$ & $78.71 \%$ & $63.88 \%$ & $91.26 \%$ \\
\hline 7.00 & $75.55 \%$ & $75.08 \%$ & $76.56 \%$ & $61.93 \%$ & $88.47 \%$ \\
\hline 6.75 & $73.22 \%$ & $72.64 \%$ & $74.45 \%$ & $60.02 \%$ & $85.74 \%$ \\
\hline 6.50 & $70.94 \%$ & $70.26 \%$ & $72.37 \%$ & $58.14 \%$ & $83.06 \%$ \\
\hline 6.25 & $68.70 \%$ & $67.94 \%$ & & $56.31 \%$ & $80.45 \%$ \\
\hline 6.00 & $66.52 \%$ & $65.67 \%$ & $68.34 \%$ & $54.52 \%$ & $77.89 \%$ \\
\hline Average effect of $1 \%$ increase & $9.75 \%$ & $10.22 \%$ & $8.77 \%$ & $7.99 \%$ & $11.42 \%$ \\
\hline \multicolumn{6}{|c|}{ Panel B: Salary Growth Rate Assumption (median observed value is $5.68 \%$ ) } \\
\hline 7.00 & $83.18 \%$ & $84.57 \%$ & $81.04 \%$ & $68.18 \%$ & $97.40 \%$ \\
\hline 6.75 & $83.46 \%$ & $84.53 \%$ & $81.81 \%$ & $68.41 \%$ & $97.73 \%$ \\
\hline 6.50 & $83.81 \%$ & $84.59 \%$ & $82.61 \%$ & $68.70 \%$ & $98.14 \%$ \\
\hline 6.25 & $84.23 \%$ & $84.75 \%$ & $83.44 \%$ & $69.04 \%$ & $98.63 \%$ \\
\hline 6.00 & $84.71 \%$ & $84.99 \%$ & $84.28 \%$ & $69.44 \%$ & $99.19 \%$ \\
\hline 5.75 & $85.24 \%$ & $85.30 \%$ & $85.15 \%$ & $69.87 \%$ & $99.82 \%$ \\
\hline 5.50 & $85.82 \%$ & $85.68 \%$ & $86.04 \%$ & $70.34 \%$ & $100.49 \%$ \\
\hline 5.25 & $86.44 \%$ & $86.11 \%$ & $86.94 \%$ & $70.85 \%$ & $101.22 \%$ \\
\hline 5.00 & $87.09 \%$ & $86.60 \%$ & $87.85 \%$ & $71.39 \%$ & $101.98 \%$ \\
\hline 4.75 & $87.78 \%$ & $87.13 \%$ & $88.78 \%$ & $71.95 \%$ & $102.79 \%$ \\
\hline 4.50 & $88.50 \%$ & $87.70 \%$ & $89.71 \%$ & $72.54 \%$ & $103.63 \%$ \\
\hline Average effect of $1 \%$ increase & $-2.13 \%$ & $-1.25 \%$ & $-3.47 \%$ & $-1.75 \%$ & $-2.49 \%$ \\
\hline \multicolumn{6}{|c|}{ Panel C: Cost Method (EAN is the most commonly observed type) } \\
\hline EAN & $85.40 \%$ & $85.40 \%$ & $85.40 \%$ & $70.00 \%$ & $100.00 \%$ \\
\hline PUC & $92.11 \%$ & $92.84 \%$ & $90.51 \%$ & $75.50 \%$ & $107.85 \%$ \\
\hline \multicolumn{6}{|c|}{ Panel D: Mortality Tables (RP-2000 with projection is the most commonly observed type) } \\
\hline RP-2000 & $87.66 \%$ & $87.77 \%$ & $87.46 \%$ & $71.85 \%$ & $102.65 \%$ \\
\hline RP-2000 with projection & $85.40 \%$ & $85.40 \%$ & $85.40 \%$ & $70.00 \%$ & $100.00 \%$ \\
\hline RP-2014 & $80.66 \%$ & $80.46 \%$ & $81.03 \%$ & $66.12 \%$ & $94.45 \%$ \\
\hline
\end{tabular}

Note: Shaded cells all represent the plan at median conditions (near median for salary growth rate). All values are funding ratios (percent of liabilities that are covered by asset holdings). 
Table 5. Effect of Actuarial Input Changes on the ARC/Payroll

\begin{tabular}{|c|c|c|c|c|c|}
\hline \multirow[b]{2}{*}{ Actuarial Input } & \multicolumn{3}{|c|}{$\begin{array}{l}\text { Assets in median condition are set to } \\
\text { an } 85.4 \% \text { funding ratio }\end{array}$} & \multirow{2}{*}{$\begin{array}{l}\text { Assets in } \\
\text { median } \\
\text { condition } \\
\text { set to a } \\
70 \% \\
\text { funding } \\
\text { ratio } \\
\text { (4) }\end{array}$} & \multirow{2}{*}{$\begin{array}{c}\text { Assets in } \\
\text { median } \\
\text { condition } \\
\text { set to a } \\
100 \% \\
\text { funding } \\
\text { ratio } \\
\text { (5) }\end{array}$} \\
\hline & $\begin{array}{c}\text { Average } \\
\text { age for } \\
\text { Active } \\
\text { participants } \\
\text { is } 45 \\
\text { (1) }\end{array}$ & $\begin{array}{c}\text { Active } \\
\text { participant } \\
\text { ages are } \\
\text { skewed } \\
\text { younger } \\
(2)\end{array}$ & $\begin{array}{c}\text { Active } \\
\text { participant } \\
\text { ages are } \\
\text { skewed } \\
\text { mature } \\
\text { (3) }\end{array}$ & & \\
\hline \multicolumn{6}{|c|}{ Panel A: Discount Rates (median observed value is 8\%) } \\
\hline 8.75 & $11.67 \%$ & $11.37 \%$ & $12.35 \%$ & $19.58 \%$ & $4.18 \%$ \\
\hline 8.50 & $13.54 \%$ & $13.27 \%$ & $14.15 \%$ & $21.27 \%$ & $6.21 \%$ \\
\hline 8.25 & $15.43 \%$ & $15.20 \%$ & $15.97 \%$ & $22.99 \%$ & $8.27 \%$ \\
\hline 8.00 & $17.35 \%$ & $17.16 \%$ & $17.81 \%$ & $24.74 \%$ & $10.35 \%$ \\
\hline 7.75 & $19.31 \%$ & $19.15 \%$ & $19.68 \%$ & $26.53 \%$ & $12.47 \%$ \\
\hline 7.50 & $21.30 \%$ & $21.18 \%$ & $21.59 \%$ & $28.35 \%$ & $14.62 \%$ \\
\hline 7.25 & $23.33 \%$ & $23.25 \%$ & $23.52 \%$ & $30.21 \%$ & $16.81 \%$ \\
\hline 7.00 & $25.39 \%$ & $25.36 \%$ & $25.49 \%$ & $32.11 \%$ & $19.03 \%$ \\
\hline 6.75 & $27.50 \%$ & $27.51 \%$ & $27.50 \%$ & $34.05 \%$ & $21.29 \%$ \\
\hline 6.50 & $29.65 \%$ & $29.71 \%$ & $29.54 \%$ & $36.04 \%$ & $23.60 \%$ \\
\hline 6.25 & $31.85 \%$ & $31.96 \%$ & $31.63 \%$ & $38.07 \%$ & $25.95 \%$ \\
\hline 6.00 & $34.10 \%$ & $34.26 \%$ & $33.76 \%$ & $40.16 \%$ & $28.35 \%$ \\
\hline Average effect of $1 \%$ increase & $-8.15 \%$ & $-8.32 \%$ & $-7.78 \%$ & $-7.48 \%$ & $-8.79 \%$ \\
\hline \multicolumn{6}{|c|}{ Panel B: Salary Growth Rate Assumption (median observed value is 5.68\%) } \\
\hline 7.00 & $24.33 \%$ & $22.79 \%$ & $27.33 \%$ & $31.72 \%$ & $17.33 \%$ \\
\hline 6.75 & $22.88 \%$ & $21.65 \%$ & $25.27 \%$ & $30.26 \%$ & $15.87 \%$ \\
\hline 6.50 & $21.48 \%$ & $20.55 \%$ & $23.33 \%$ & $28.87 \%$ & $14.48 \%$ \\
\hline 6.25 & $20.16 \%$ & $19.48 \%$ & $21.52 \%$ & $27.54 \%$ & $13.16 \%$ \\
\hline 6.00 & $18.89 \%$ & $18.44 \%$ & $19.82 \%$ & $26.28 \%$ & $11.89 \%$ \\
\hline 5.75 & $17.68 \%$ & $17.43 \%$ & $18.24 \%$ & $25.07 \%$ & $10.68 \%$ \\
\hline 5.50 & $16.53 \%$ & $16.46 \%$ & $16.75 \%$ & $23.91 \%$ & $9.53 \%$ \\
\hline 5.25 & $15.43 \%$ & $15.52 \%$ & $15.35 \%$ & $22.81 \%$ & $8.43 \%$ \\
\hline 5.00 & $14.37 \%$ & $14.61 \%$ & $14.04 \%$ & $21.76 \%$ & $7.37 \%$ \\
\hline 4.75 & $13.37 \%$ & $13.73 \%$ & $12.81 \%$ & $20.75 \%$ & $6.37 \%$ \\
\hline 4.50 & $12.41 \%$ & $12.88 \%$ & $11.65 \%$ & $19.79 \%$ & $5.41 \%$ \\
\hline Average effect of $1 \%$ increase & $4.77 \%$ & $3.96 \%$ & $6.27 \%$ & $4.77 \%$ & $4.77 \%$ \\
\hline \multicolumn{6}{|c|}{ Panel C: Cost Method (EAN is the most commonly observed type) } \\
\hline EAN & $17.35 \%$ & $17.16 \%$ & $17.81 \%$ & $24.74 \%$ & $10.35 \%$ \\
\hline PUC & $16.42 \%$ & $15.24 \%$ & $19.02 \%$ & $23.81 \%$ & $9.42 \%$ \\
\hline \multicolumn{6}{|c|}{ Panel D: Mortality Tables (RP-2000 with projection is the most commonly observed type) } \\
\hline RP-2000 & $15.86 \%$ & $15.64 \%$ & $16.35 \%$ & $23.24 \%$ & $8.86 \%$ \\
\hline RP-2000 with projection & $17.35 \%$ & $17.16 \%$ & $17.81 \%$ & $24.74 \%$ & $10.35 \%$ \\
\hline RP-2014 & $20.76 \%$ & $20.61 \%$ & $21.16 \%$ & $28.15 \%$ & $13.76 \%$ \\
\hline
\end{tabular}

Notes: Shaded cells all represent the plan at median conditions (near median for salary growth rate). All values reported as percent of covered payroll. 
Figure 1. Variance between Simulated and Observed Costs and Liabilities

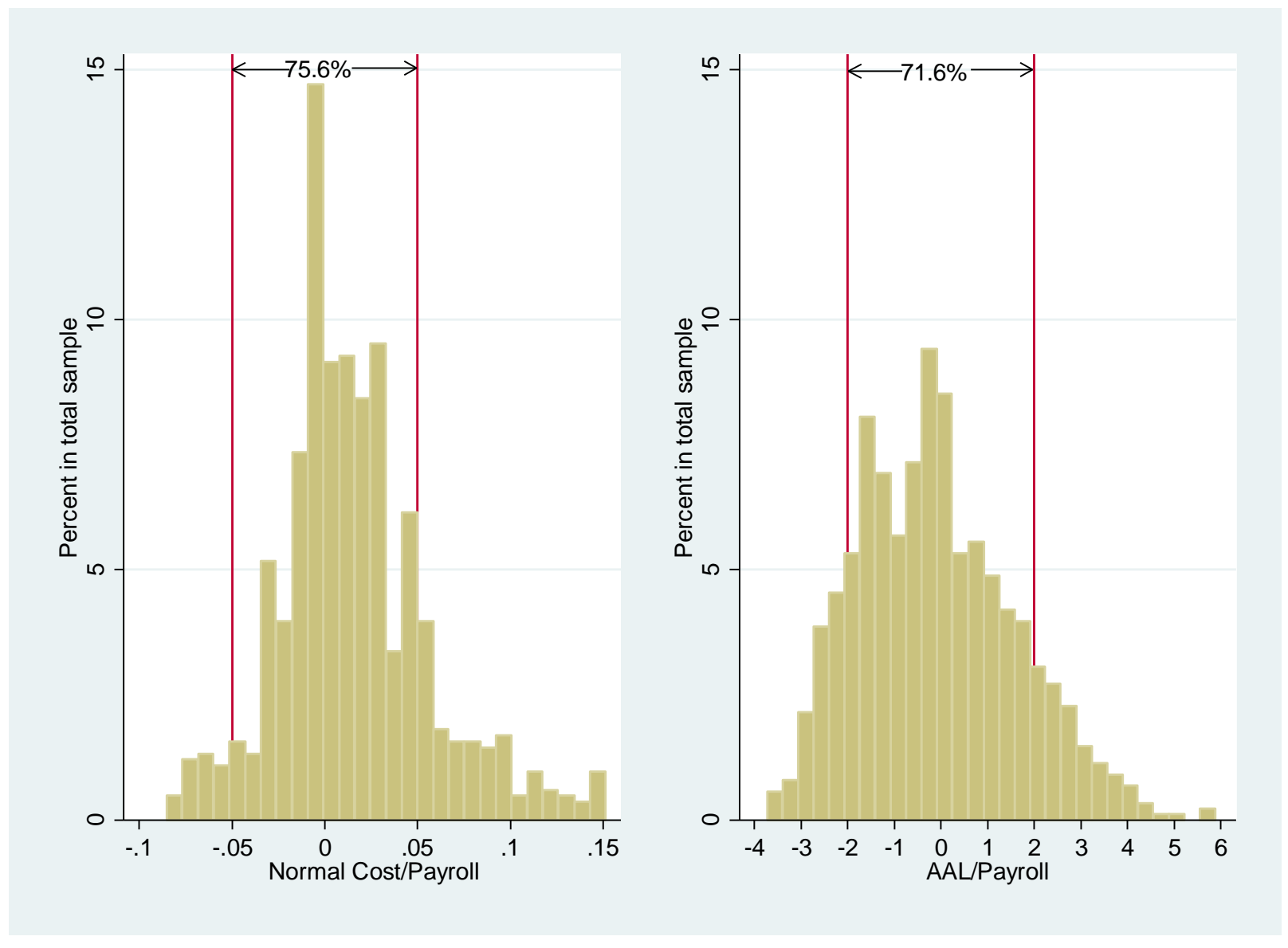

Notes: Variance $=($ Observed values - Simulated values $)$. Simulations are based on 880 normal costs and 926 actuarially accrued liabilities (AALs). 
Figure 2. Simulated Funding Ratios Over 20 Years Based on Different Discount Rates*

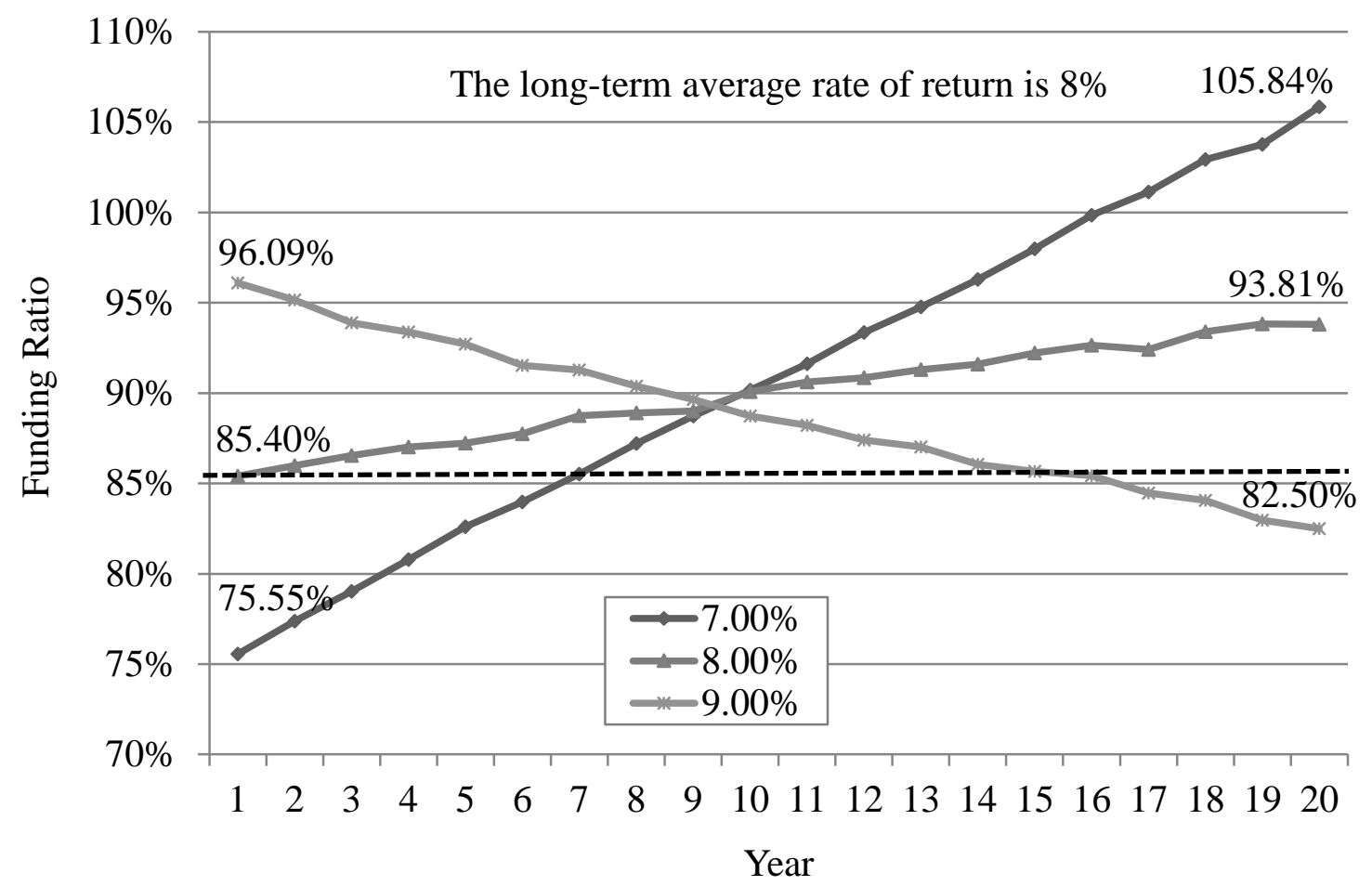

Figure 3. Simulated Contribution Rates Over 20 Years Based on Different Discount Rates*

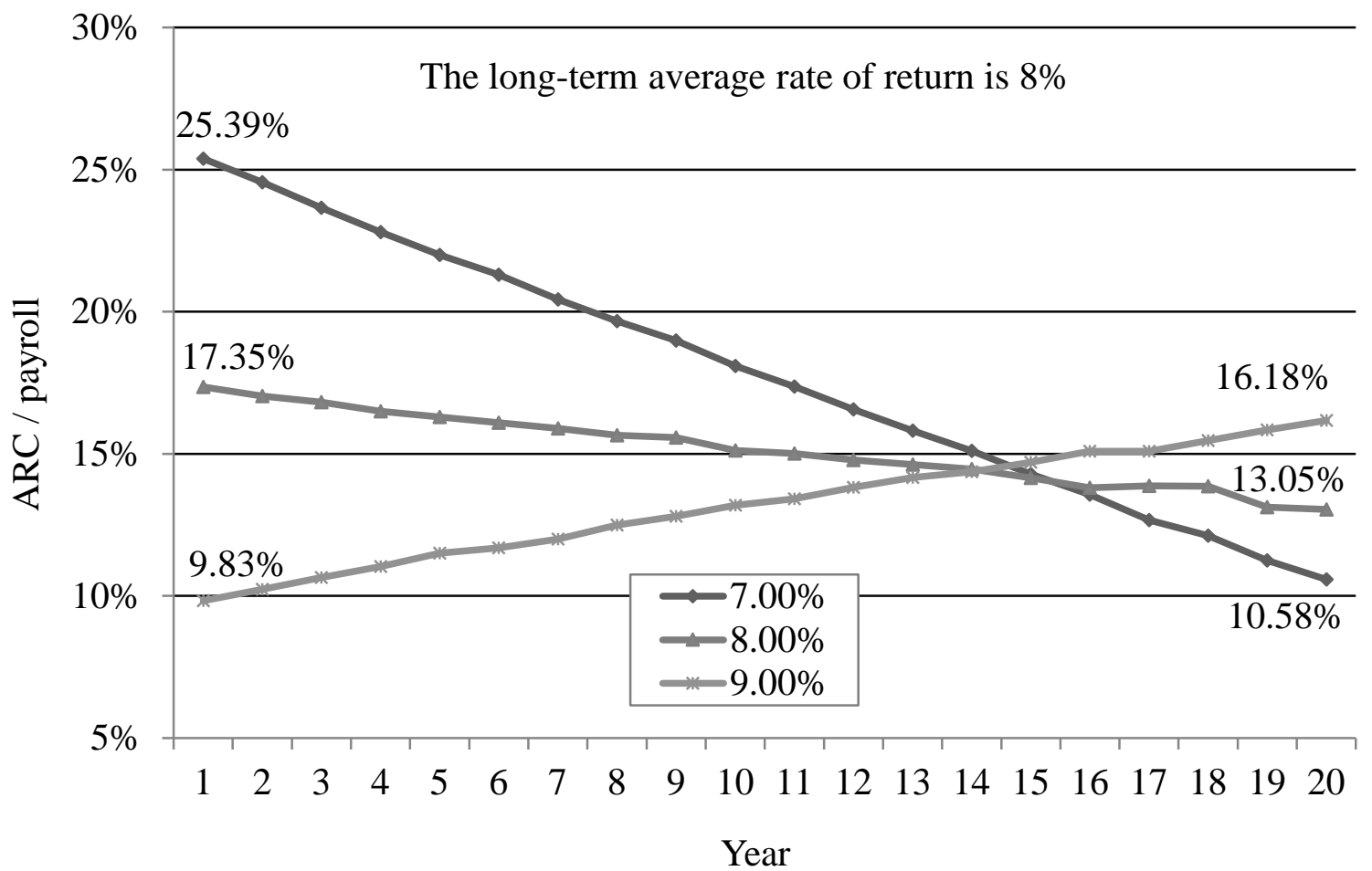

*Notes: Simulations are based on 10,000 iterations. 
Figure 4. Comparison of the Effects of Changing Salary Growth Rate Assumptions under Different Conditions

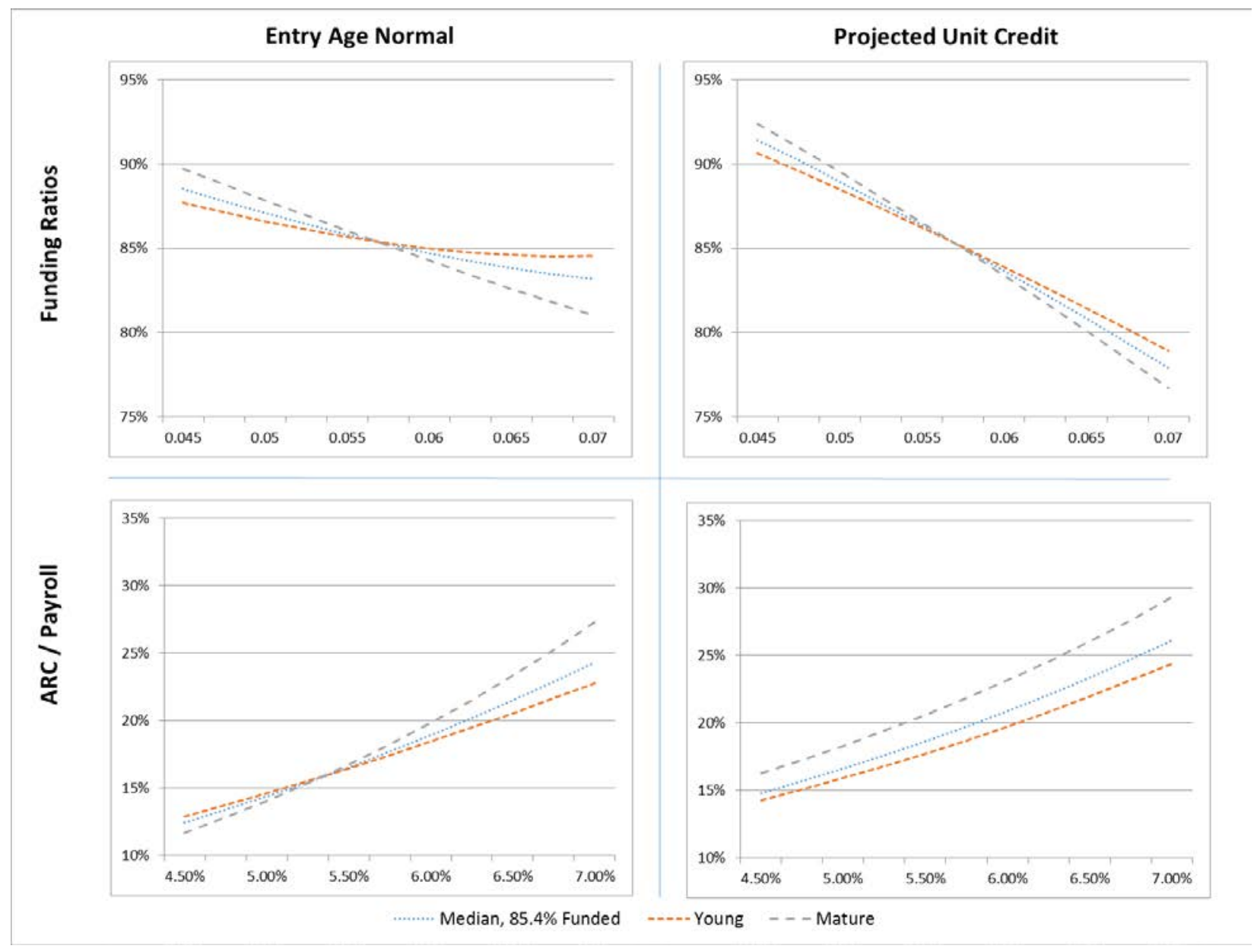




\section{RECENT WORKING PAPERS FROM THE CENTER FOR RETIREMENT RESEARCH AT BOSTON COLLEGE}

Why Are U.S. Households Claiming Social Security Later?

Wenliang Hou, Alicia H. Munnell, Geoffrey T. Sanzenbacher, and Yinji Li, April 2017

Rising Inequality in Life Expectancy by Socioeconomic Status

Geoffrey T. Sanzenbacher, Anthony Webb, Candace M. Cosgrove, and Natalia S. Orlova, April 2017

The Effect of Job Mobility on Retirement Timing by Education

Geoffrey T. Sanzenbacher, Steven A. Sass, and Christopher M. Gillis, February 2017

Would Reducing the Price of Employing an Older Worker Improve Labor Market Outcomes by Socioeconomic Status? Evidence from Health Insurance Premium Restrictions

Matthew S. Rutledge and Caroline V. Crawford, December 2016

The Impact of Massachusetts Health Insurance Reform on Labor Mobility

Norma B. Coe, Wenliang Hou, Alicia H. Munnell, Patrick J. Purcell, and Matthew S. Rutledge, December 2016

Work, Retirement, and Social Networks at Older Ages

Eleonora Patacchini and Gary V. Engelhardt, November 2016

Calculating Expected Social Security Benefits by Race, Education, and Claiming Age

Geoffrey T. Sanzenbacher and Jorge D. Ramos-Mercado, November 2016

Do Late-Career Wages Boost Social Security More for Women than Men?

Matthew S. Rutledge and John E. Lindner, November 2016

Cognitive Impairment and Social Security's Representative Payee Program

Anek Belbase and Geoffrey T. Sanzenbacher, November 2016

How Would Reducing the Price of Older Workers Improve Labor Market Outcomes by Socioeconomic Status? Evidence from Health Insurance Premium Restrictions Matthew S. Rutledge and Caroline V. Crawford, October 2016

An Overview of the Pension/OPEB Landscape

Alicia H. Munnell and Jean-Pierre Aubry, October 2016

All working papers are available on the Center for Retirement Research website (http://crr.bc.edu) and can be requested by e-mail (crr@bc.edu) or phone (617-552-1762). 